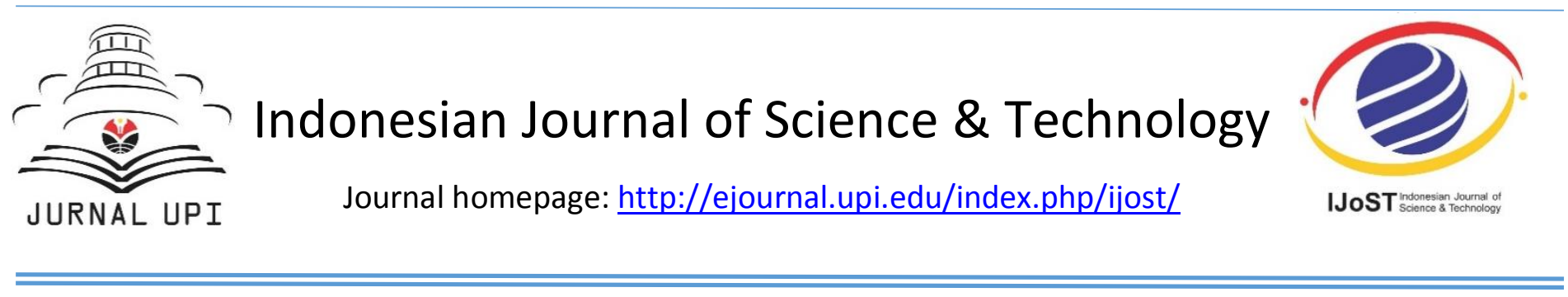

\title{
Process Design and Modelling of the Production of Butyl Cellosolve Acetate and EO-3 Phosphate Ester
}

\author{
Lupete K. Bhullar ${ }^{1}$, Zulpan Adi Putra ${ }^{2}$ \\ Department of Chemical Engineering, Universiti Teknologi PETRONAS, Bandar Seri Iskandar, 32610, Perak, \\ Malaysia \\ * Correspondence: lupetebhullar@gmail.com
}

A B S T R A C T

A chemical company has identified that Butyl Cellosolve Acetate (BCA) and EO-3 Phosphate Ester (EO-3 PE) esters have significant potential in a large variety of applications. However, there is limited information in existing practices involving these particular grades of esters. Hence, the aim of the present work is to develop the process design for the production of these two esters. Within the development stage, the technical and economic challenges of the production processes are evaluated and compared. The results show that, among other things, the BCA process shows the formation of azeotropic mixtures which causes the separation process to be difficult. On the other hand, EO-3 $P E$ shows the formation of aqueous phosphoric acid that is also difficult to separate. Fortunately, this aqueous phosphoric acid can be sold, which then increase the economic attractiveness of the developed process. Monte Carlo simulation were performed to account some uncertainties such as CAPEX estimate, raw material prices and product prices. This simulation shows that the developed BCA process has a significant chance to be nonprofitable, while the economic potential of the EO-3 PE process is at least $200 \%$ higher than that of the BCA process in all scenarios.

C 2017 Tim Pengembang Journal UPI
ARTICLE INFO

Article History:
Submitted/Received 09 May 2017
First Revised 09 Jul 2017
Accepted 29 Aug 2017
First Available online 30 Aug 2017
Publication Date 01 Sep 2017

Keyword:

Butyl Cellosolve Acetate (BCA), EO-3 Phosphate Ester (EO-3 PE),

Esterification,

Process simulation,

Azeotropic mixtures,

Aqueous phosphoric acid,

CAPEX,

OPEX,

Economic potential,

Economies of scale,

Monte Carlo simulation. 


\section{INTRODUCTION}

There is an ever-growing demand by consumers for industrial products such as detergents, soaps, and dyes. Therefore, a variety of chemical products are continuously manufactured by industries to feed this demand (Stine, 1933). A chemical company has identified two esters for this purpose, which can be manufactured from their existing products. The identified esters are Butyl Cellosolve Acetate (BCA) and EO-3 Phosphate Ester (EO-3 PE). BCA is produced by reacting butyl cellosolve with acetic acid, while EO-3 PE is produced by reacting Tergitol 26L-3 with phosphoric acid (Mitsunobu \& Yamada, 1967).

The reaction routes to produce these esters were explored and their performance were compared. It was found that the information on producing BCA and EO-3 PE are very limited compared to other grades of esters (Li, 1990).

Therefore, the aim of this work is to develop processes to produce BCA and EO-3 $P E$. The developed processes were based on previous patents of the reactions (Knee et al., 1995; Tsuyutani, et al., 2002). The processes were then simulated in Aspen HYSYS. The mass and energy balances were used both to size the main process equipment for estimation of the capital expenditure (CAPEX) and the operational cost (OPEX). During the development process, technical challenges were discovered and discussed. Cost estimation based on the capital investment and operational cost was used to analyse the profitability of the processes. Lastly, sensitivity analysis was performed to analyse the effect of uncertainties in the CAPEX and OPEX estimations.

\section{PROCESS DESIGN METHODOLOGY}

\subsection{Methodology flowchart}

The summary of the research methodology for both processes as explained above is shown in Figure $\mathbf{1}$ below. In general, the methodology followed industrial practices where the process routes were selected, process configurations were developed, capital and operational expenditures (CAPEX and OPEX, respectively) were estimated, and then sensitivity analysis were performed. Details of the methodology were explained elsewhere (D'Alessandro, 2010; Putra, 2016)

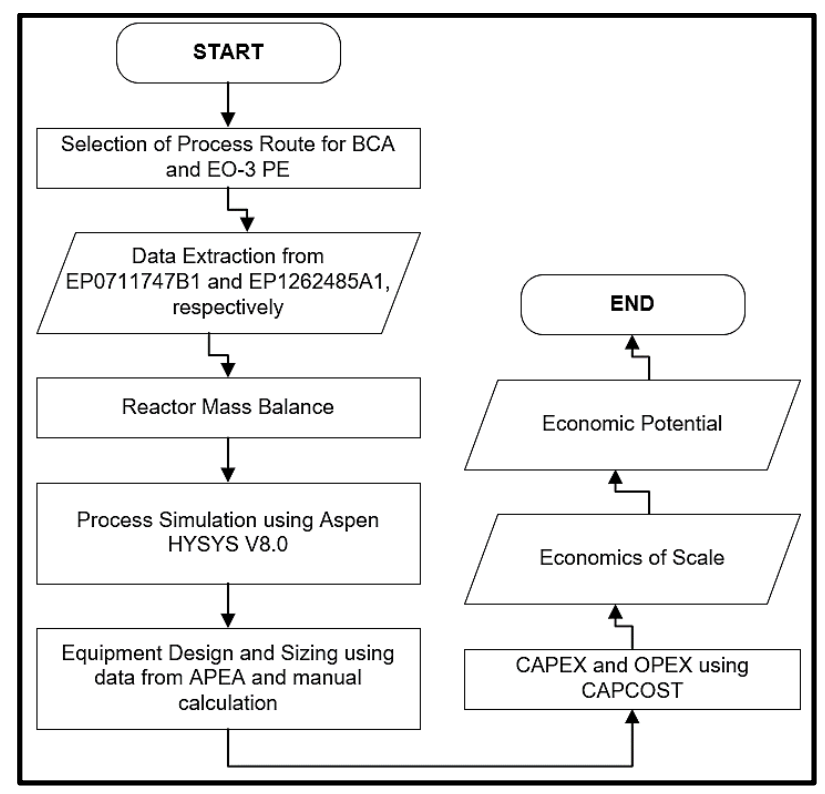

Figure 1. Methodology flowchart 


\subsection{Reactions involved}

\subsubsection{Butyl Cellosolve into BCA}

The first ester to produce is the BCA from a raw material called butyl cellosolve. Butyl Cellosolve is one of the products of a refining system to separate a crude Butyl Glycol Ether (BGE) stream. In this process, Butyl Cellosolve is reacted with acetic acid in a lab scale continuous reactor (Knee et al., 1995). The reaction data was gathered from a patent published by Union Carbide (patent no.: EP0711747B1) and was used as the starting point in the process design. This patent was selected as a reference because it provides all the necessary data in a simple but detailed manner. The data provided gives the compositions of product in the overhead and bottom of the reactor and the operating conditions.

According to the patent, the following reactions 1,2 and 3 are involved in the esterification process to produce BCA.

Main reaction

Butyl Cellosolve + Acetic Acid $\rightarrow$ BCA + Water (1)

$\mathrm{C}_{4} \mathrm{H}_{9} \mathrm{OCH}_{2} \mathrm{CH}_{2} \mathrm{CHO}+\mathrm{CH}_{3} \mathrm{COOH}$

$\rightarrow \mathrm{C}_{4} \mathrm{H}_{9} \mathrm{OCH}_{2} \mathrm{CH}_{2} \mathrm{OC}(\mathrm{O}) \mathrm{CH}_{3}$

$+\mathrm{H}_{2} \mathrm{O}$

Side reaction 1

Butyl Cellosolve + Acetic Acid $\rightarrow$ Lights

$\mathrm{C}_{4} \mathrm{H}_{9} \mathrm{OCH}_{2} \mathrm{CH}_{2} \mathrm{CHO}+\mathrm{CH}_{3} \mathrm{COOH} \rightarrow$ Lights

Side reaction 2

Butyl Cellosolve + Acetic Acid $\rightarrow$ Heavies $\mathrm{C}_{4} \mathrm{H}_{9} \mathrm{OCH}_{2} \mathrm{CH}_{2} \mathrm{CHO}+\mathrm{CH}_{3} \mathrm{COOH} \rightarrow$ Heavies

(3)

The reaction occurs in the presence of Dodecyl Benzene Sulfonic Acid (DBSA) catalyst. DBSA is a long chain alkyl substituted aryl sulfonic acid. It is mentioned that the DBSA is the most preferred catalyst because of its high selectivity and it can withstand high temperatures (Knee et al., 1995). It is also reported that higher purity of BCA results in better color, less corrosion and reduced fouling property in the ester.

\subsubsection{Tergitol 26L-3 into EO-3 Phosphate Ester}

EO-3 $P E$ is produced from a raw material called Tergitol $26 \mathrm{~L}-3$. The Tergitol $26 \mathrm{~L}-3$ is esterified with phosphoric acid. Tergitol 26L3 is a chemical compound that consist of 10 to 16 carbon atoms in the alkyl group and 3 moles of ethylene oxide. This product is a mixture of many components. Hence, a fatty alcohol ethoxylate, forming the majority of the Tergitol 26L-3, was taken as the model component. This component is made up of an undecyl alcohol (11 carbon atoms) and 3 moles of ethylene oxide. The reaction data was gathered from a published patent (Pintarič \& Kravanja et al., 2015) and was used as the starting point in the process design. This patent is chosen among the other available patents because the yield to the main component, Di-Phosphate Ester (di-PE), is the highest. The process suggested by the patent involves several reaction steps, as follows.

Reaction 1

Tergitol 26L-3 + Phosphoric Acid $\rightarrow$

mono-PE + Water

$\mathrm{CH}_{3}\left(\mathrm{CH}_{2}\right)_{9} \mathrm{CH}_{2}\left(\mathrm{OCH}_{2} \mathrm{CH}_{2}\right)_{3} \mathrm{OH}+\mathrm{H}_{3} \mathrm{PO}_{4} \rightarrow \mathrm{O}$ $=\mathrm{P}(\mathrm{OH})_{2} \mathrm{OR}+\mathrm{H}_{2} \mathrm{O}$

Reaction 2

2 Tergitol 26L-3 + Phosphoric Acid $\rightarrow$

di-PE + Water

$2 \mathrm{CH}_{3}\left(\mathrm{CH}_{2}\right)_{9} \mathrm{CH}_{2}\left(\mathrm{OCH}_{2} \mathrm{CH}_{2}\right)_{3} \mathrm{OH}+\mathrm{H}_{3} \mathrm{PO}_{4} \rightarrow \mathrm{O}$ $=\mathrm{P}(\mathrm{OR})_{2} \mathrm{OH}+\mathrm{H}_{2} \mathrm{O}$

Reaction 3

2 Tergitol 26L-3 + 5 Phosphorus Pentoxide $\rightarrow$

2 di-PE

$2 \mathrm{CH}_{3}\left(\mathrm{CH}_{2}\right)_{9} \mathrm{CH}_{2}\left(\mathrm{OCH}_{2} \mathrm{CH}_{2}\right)_{3} \mathrm{OH}+5 \mathrm{P}_{2} \mathrm{O}_{5} \rightarrow 2 \mathrm{O}$ $=\mathrm{P}(\mathrm{OR})_{2} \mathrm{OH}$

Reaction 4

Di-Phosphate Ester + Water $\rightarrow 2$ mono-PE (7)

$\mathrm{O}=\mathrm{P}(\mathrm{OR})_{2} \mathrm{OH}+\mathrm{H}_{2} \mathrm{O} \rightarrow 2 \mathrm{O}=\mathrm{P}(\mathrm{OH})_{2} \mathrm{OR}$

$\underline{\text { Reaction } 5}$

Phosphorus Pentoxide +3 Water $\rightarrow$

2 Phosphoric Acid

$\mathrm{P}_{2} \mathrm{O}_{5}+3 \mathrm{H}_{2} \mathrm{O} \rightarrow \mathrm{H}_{3} \mathrm{PO}_{4}$ 
Tabel 1. Reactor outlet composition (wt\%).

\begin{tabular}{lcc}
\hline Products & Overhead & Bottom \\
\hline Acetic Acid & 9.40 & 4.91 \\
\hline Butyl Cellosolve & 17.95 & 8.12 \\
\hline $\mathrm{BCA}$ & 65.25 & 85.44 \\
\hline $\mathrm{DBSA}$ (wt\% $\left.\mathrm{H}_{2} \mathrm{SO}_{4}\right)$ & - & $0.41-0.37$ \\
\hline $\mathrm{H}_{2} \mathrm{O}$ & 7.09 & 0.31 \\
\hline Total Lights (by-product) & 0.07 & 0.09 \\
\hline Total Heavies (by-product) & 0.15 & 0.29 \\
\hline Total By-Products & 0.22 & 0.38 \\
\hline
\end{tabular}

Tabel 2. Operating conditions of the reaction.

\begin{tabular}{ll}
\hline Operating Conditions & Information \\
\hline Temperature $\left({ }^{\circ} \mathrm{C}\right)$ [overhead] & $:(135-137)$ \\
\hline Temperature $\left({ }^{\circ} \mathrm{C}\right)[$ bottom] & $:(145-149)$ \\
\hline Pressure $(\mathrm{kPa})$ & $: 101$ \\
\hline Catalyst & $:$ Dodecyl Benzene Sulfonic Acid (DBSA) \\
\hline Feed ratio & $:$ Equimolar $(1: 1)$ \\
\hline Residence time & $: 2$ hours \\
\hline
\end{tabular}

Tabel 3. Flowrate $(\mathrm{kg} / \mathrm{hr})$ of feed to reactor I, II, and III for the production of EO-3 PE.

\begin{tabular}{clc}
\hline Reaction & Feed & Flow Rate (kg/hr) \\
\hline \multirow{2}{*}{ I } & Neodol 1-3 & 0.548 \\
\cline { 2 - 3 } & Phosphoric Acid & 0.043 \\
\hline II & Phosphorous Pentoxide (solid) & 0.11 \\
\hline III & Water & 0.014 \\
\hline
\end{tabular}

Tabel 4. Composition of the outlet stream of reactor III (wt\%).

\begin{tabular}{lc}
\hline Product & Composition (wt\%) \\
\hline mono-PE & 73.3 \\
\hline di-PE & 21.2 \\
\hline Phosphoric Acid & 3.8 \\
\hline Unreacted ROH & 1.5 \\
\hline
\end{tabular}

\subsection{Process Design}

\subsubsection{Butyl Cellosolve Acetate}

The reaction data to produce $\mathrm{BCA}$ is taken from the patent. Table 1 shows the outlet streams compositions while Table $\mathbf{2}$ lists the operating conditions used in the production of BCA. 
Tabel 5. Operating conditions in reactor I, II, and III.

\begin{tabular}{cll}
\hline Reaction & \multicolumn{2}{l}{ Operating Conditions } \\
\hline \multirow{3}{*}{ I } & Temperature $\left({ }^{\circ} \mathrm{C}\right)$ & $: 90$ \\
\cline { 2 - 3 } & Pressure $(\mathrm{kPa})$ & $: 101$ \\
\cline { 2 - 3 } & Residence Time $(\mathrm{hrs})$ & $: 12$ \\
\hline \multirow{3}{*}{ II } & Temperature $\left({ }^{\circ} \mathrm{C}\right)$ & $: 90$ \\
\cline { 2 - 3 } & Pressure $(\mathrm{kPa})$ & $: 2.67$ \\
\cline { 2 - 3 } & Residence Time $(\mathrm{hrs})$ & $: 8$ \\
\hline \multirow{3}{*}{ III } & Temperature $\left({ }^{\circ} \mathrm{C}\right)$ & $: 90$ \\
\cline { 2 - 3 } & Pressure $(\mathrm{kPa})$ & $: 101$ \\
\cline { 2 - 3 } & Residence Time $(\mathrm{hrs})$ & $: 3$ \\
\hline
\end{tabular}

Tabel 6. Cost factors used in the CAPEX estimate.

\begin{tabular}{ll}
\hline Bare Module Cost & Calculated using CAPCOST \\
\hline ISBL & 3 times of bare module cost \\
\hline OSBL & $30 \%$ of ISBL \\
\hline Engineering Cost & $30 \%$ of (ISBL + OSBL) \\
\hline Contingency & $20 \%$ of (ISBL + OSBL) \\
\hline WCI & $15 \%$ of (ISBL + OSBL) \\
\hline SCl & 0.06 of $\mathrm{FCl}$ \\
\hline
\end{tabular}

\subsubsection{E0-3 Phosphate Ester}

From the patent (Pintarič \& Kravanja et al., 2015), the reaction data and the operating conditions for the production of EO-3 PE is extracted. The reactions involved 3 reactors in series, namely here reaction I, II, and III. Table 3 shows the flowrate $(\mathrm{kg} / \mathrm{hr})$ of the components fed to the reactors. Table 4 and Table 5 shows the composition of the final products (outlet reactor III) and the operating conditions of all reactors.

\subsection{Economic Analysis}

From the developed process, the investment cost of main process equipment or the bare equipment cost is estimated by using CAPCOST (Deng \& Hägg 2010). From the bare cost, investment calculations follow cost factors used in the literature (Peters et al., 2002). Hence, the final CAPEX is the summation of the fixed capital investment (FCl), working capital investment (WCl) and start-up capital investment $(\mathrm{SCl})$. $\mathrm{FCl}$ includes the cost of the manufacturing plant (ISBL), cost of improvements of site (OSBL), direct and indirect costs for each equipment (bare module cost), cost of contractors and design (engineering cost) and contingency cost. These factors are shown in Table 6.

The operating expenditure (OPEX) is the summation of variable, fixed and plant overhead costs. Variable costs include the cost of utilities and other various additional costs (miscellaneous). The unit cost of utilities was taken from Aspen Process Economic Analyser (APEA) (Dal Pont, 2014 ). Fixed and overhead costs are taken from cost factors as tabulated in Table 7. 
171 | Indonesian Journal of Science \& Technology, Volume 2 Issue 2, September 2017 Hal 166-182

Tabel 7. Cost factors used in the OPEX estimation(M. Peters et al., 2002; J.R. Couper , 2003)

\begin{tabular}{ll}
\hline Cost of Utilities & Calculated using APEA \\
\hline Miscellaneous & $10 \%$ of utility cost \\
\hline Cost of maintenance & $2 \%$ of $\mathrm{FCl}$ \\
\hline Operating supplies & $10 \%$ of total annual raw material cost \\
\hline Operating labor & $15 \%$ of total product sales \\
\hline Lab costs & $10 \%$ of operating labor \\
\hline Local taxes/patents & $1 \%$ of $\mathrm{FCl}$ \\
\hline Cost of insurance & $0.4 \%$ of $\mathrm{FCl}$ \\
\hline Administrative cost & $15 \%$ of $($ cost of maintenance + operating labor) \\
\hline Distribution and marketing & $10 \%$ of $\mathrm{FCl}$ \\
\hline Research and development & $5 \%$ of $\mathrm{FCl}$ \\
\hline
\end{tabular}

Tabel 8. Cost factors used in the OPEX estimation $[6,8]$

\begin{tabular}{lccc}
\hline \multicolumn{1}{c}{ Parameter } & $\begin{array}{c}\text { Minimum } \\
\text { deviation }\end{array}$ & $\begin{array}{c}\text { Maximum } \\
\text { deviation }\end{array}$ & Remarks \\
\hline Raw material price & $-30 \%$ & $+30 \%$ & Price fluctuations are assumed to be \\
\hline Product price & $-30 \%$ & $+30 \%$ & from $-30 \%$ to $+30 \%$ \\
\hline OPEX & $-30 \%$ & $+30 \%$ & \\
\hline CAPEX & $-30 \%$ & $+50 \%$ & $\begin{array}{l}\text { CAPEX estimation accuracy at this } \\
\text { level of conceptual work is }-30 \% /+50 \%\end{array}$ \\
\hline
\end{tabular}

From the CAPEX and the OPEX estimations, together with the prices of the raw materials and the products, the economic potential (EP) of the processes were calculated using Equation 9. The annual cost of CAPEX is calculated by using $10 \%$ rate of return and 20 years of running plant.

$E P\left(\frac{\$}{y r}\right)=$

Product sales-Raw Material Cost-OPEX-CAPEX (9)

\subsection{Sensitivity Analysis}

All the above mentioned economic terms (CAPEX, OPEX, and EP) are evaluated for various plant capacity. This is performed to estimate the economy of scale of the processes. Then, for further sensitivity analysis, the scale of the plant is selected at the point where the capacity that the plants do not have the advantage of the scale anymore.
Based on the above selected capacity, further sensitivity analysis via Monte Carlo simulations are done to evaluate the effects of several uncertain parameters. Monte Carlo simulation is preferred because this method can evaluate multiple random uncertainties in one case. The simulation is done for 1000 random cases.

In this conceptual study, the accuracy of the CAPEX and the OPEX estimates are considered, together with the chemical prices (raw materials and products. The range of deviations from the selected capacity (referred as base-case) are shown in Tabel 8. Based on these deviations, the EP is calculated in all of those 1000 random cases during the Monte Carlo simulations. 


\section{RESULTS AND DISCUSSION}

\subsection{Butyl Cellosolve Acetate}

\subsubsection{Process Flow Diagram}

The developed process flow diagram (PFD) of BCA process is shown in Figure 1 The simulation was conducted using ASPEN HYSYS Version 8.8. The components involved are acetic acid, butyl cellosolve, BCA, water, DBSA as catalyst, lights, and heavies. UNIQUAC Ideal is chosen as the fluid package because it is a suitable model for the prediction of activity coefficients for the separation of highly non-ideal multicomponent liquid mixtures that forms multiple azeotropes.

\subsubsection{Process Description}

The esterification reaction occurs in a conversion reactor (R-101). Butyl cellosolve and acetic acid are fed into R-101 along with catalyst, DBSA. The feed enters at an arbitrary total mass flowrate of $1000 \mathrm{~kg} / \mathrm{hr}$. The products formed include BCA, water, lights \& heavies by-products, and unreacted raw materials. Bottom liquid product Table1 is drawn as stream 3.

This stream is then purified in a train of distillation columns (T-101, T-103, and T104). The first column, T-101, is to separate all of the lighter products such as acetic acid, water, unreacted butyl cellosolve, and other by-products identified as light components in Table 1. This vapor mixture, stream 6, contains components that are difficult to separate such as acetic acid and water, butyl cellosolve and water, as well as the lights and water. The liquid distillate, stream 7, contains mostly unreacted butyl cellosolve, which is then recycled back to the reactor. Detailed on how the mass balance around the reactor is calculated is explained elsewhere (Borole, 2007). Next, T-103 is used to separate the product BCA from the top of the column, while the heavies and the DBSA catalyst is sent to T-103. Then, in the T-103, the DBSA catalyst is taken as the bottom stream and recycled back to the reactor.

The overhead outlet of the reactor, stream 2, is condensed and sent to column T102 to separate mostly the water. The bottom product is mostly unreacted butyl cellosolve and the BCA product, which are then recycled back to the reactor. Based on the total feed of $1000 \mathrm{~kg} / \mathrm{hr}$, with the butyl cellosolve of about $37 w t \%$, this process produces about $917 \mathrm{~kg} / \mathrm{hr}$ of BCA with the purity of more than $99.9 \mathrm{wt} \%$. Figure 2 shows the process flow diagram of the production process of BCA. A summary of the process material and energy balance is shown in Table 9. 

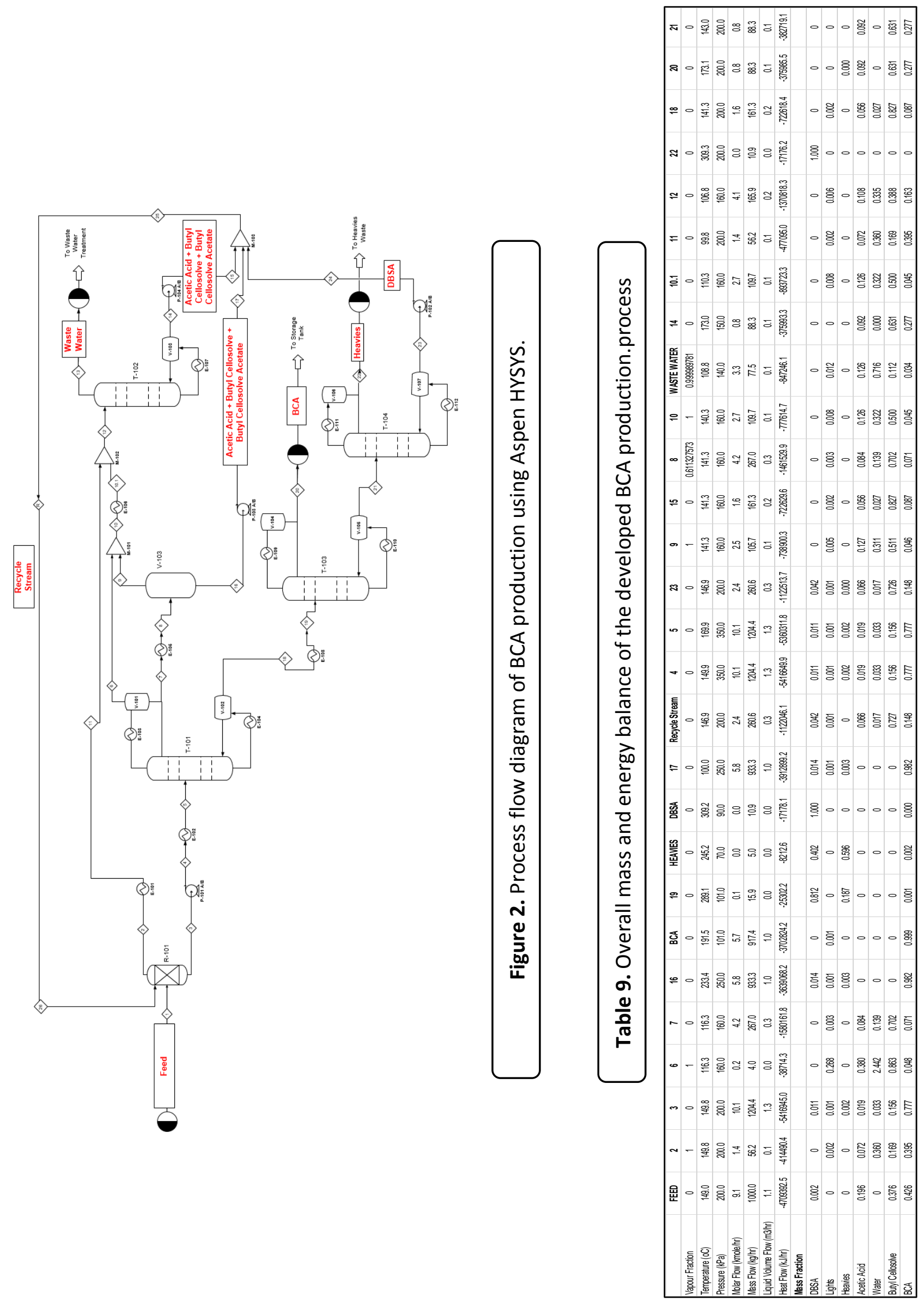


\subsubsection{Economic Analysis}

Based on the above mass and energy balance, the costs of main process equipment and the total capital investment (CAPEX) are estimated as explained above. The estimated CAPEX for the BCA process is tabulated in Table $\mathbf{1 0}$ and plotted in Figure 3. The graph shows that the lowest CAPEX per unit of plant capacity is about $\$ 2.1$ million/(ton/hr). At this capacity, about $20 \mathrm{t} / \mathrm{hr}$ of $\mathrm{BCA}$ is produced. As the product flowrate starts to increase from 20t/hr, the CAPEX per unit starts to increase because larger process equipment is not practically available. Thus, two separate process equipment have to be installed. Hence, the estimated CAPEX slightly increases. This area of the graph is called the diseconomies of scale.

Table 10. CAPEX estimate for the BCA process with different plant capacities.

\begin{tabular}{ccc}
\hline Feed (t/hr) & Product (t/hr) & CAPEX/unit (mil \$/t) \\
\hline 1 & 0.9 & 18.7 \\
\hline 2 & 1.8 & 10.3 \\
\hline 4 & 3.7 & 5.8 \\
\hline 6 & 5.5 & 4.3 \\
\hline 8 & 7.3 & 3.7 \\
\hline 10 & 9.2 & 3.1 \\
\hline 15 & 13.8 & 2.7 \\
\hline 20 & 20.3 & 2.1 \\
\hline 30 & 27.5 & 2.2 \\
\hline 50 & 45.9 & 2.4 \\
\hline 60 & 55.0 & 2.5 \\
\hline
\end{tabular}

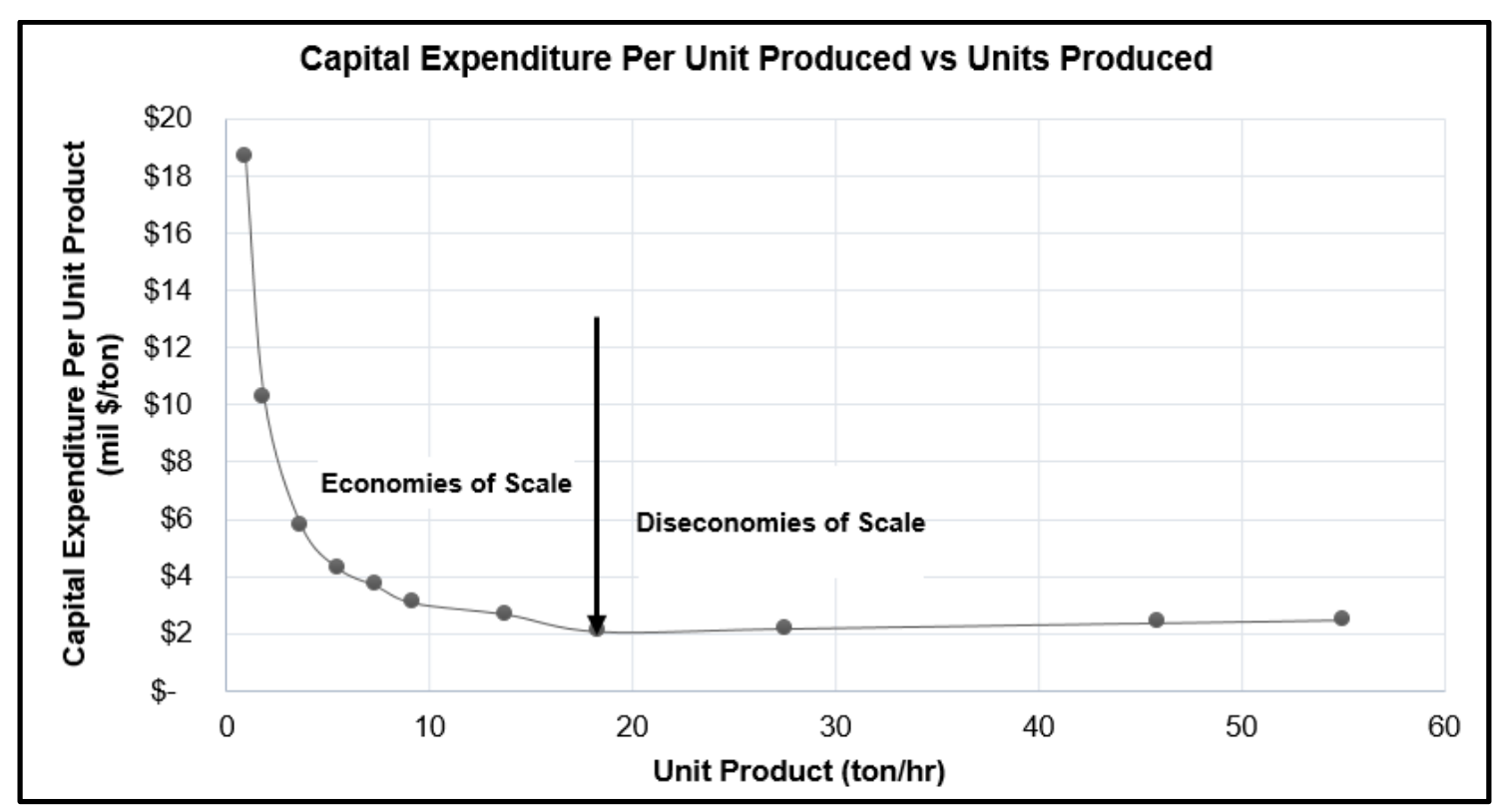

Figure 3. Economy of scale of the BCA process. 
175| Indonesian Journal of Science \& Technology, Volume 2 Issue 2, September 2017 Hal 166-182

Table 11. Raw material and product prices for the BCA production.

\begin{tabular}{lccc}
\hline \multirow{2}{*}{ Cost (\$/kg) } & \multicolumn{2}{c}{ Raw Material Cost } & Product Sale \\
\cline { 2 - 4 } & & \multicolumn{2}{c}{ Amount per hour $(\mathbf{k g} / \mathbf{h r})$} \\
\hline Acetic Acid & 0.51 & 196.42 & - \\
\hline Butyl Cellosolve & 1.14 & 375.57 & - \\
\hline DBSA & 2.47 & 2.05 & - \\
\hline BCA & 1.189 & - & 916.85 \\
\hline \multicolumn{2}{r}{ Total Cost $(\mathbf{\$} / \mathbf{h r})$} & 533.40 & 1090.14 \\
\hline \multicolumn{2}{r}{ Total Cost $\mathbf{m i l} \mathbf{\$} / \mathbf{y r})$} & 4.3 & 8.7 \\
\hline
\end{tabular}

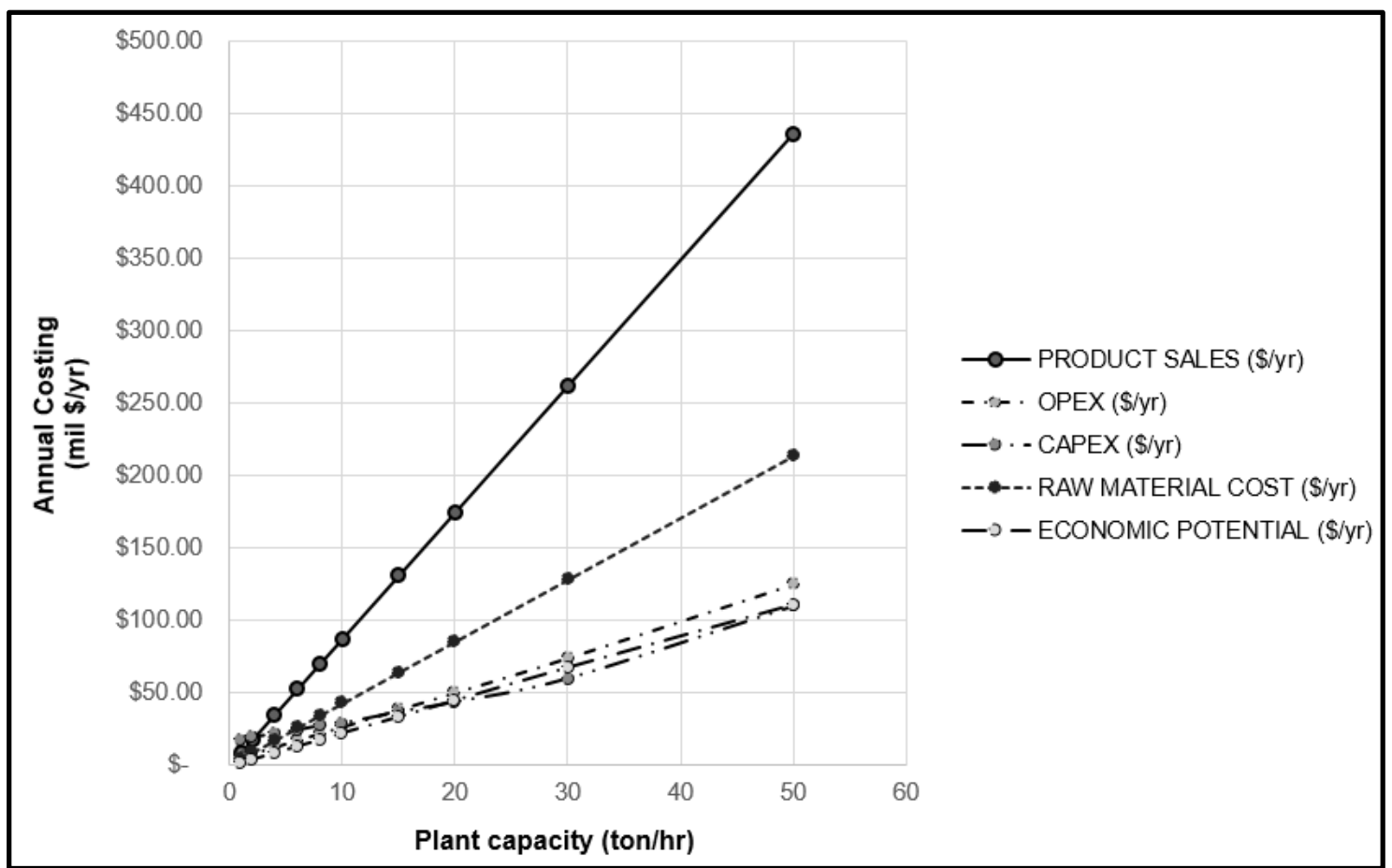

Figure 4. Annual product sales, OPEX, CAPEX, raw material cost, and EP of the BCA process.

To calculate the Economic Potential $(E P)$, cost of materials and utilities are considered. Cost of materials are taken from (Landucci, 1994))and shown in Table 11, while the utilities are calculated via Aspen Process Economic data. The estimated annualized CAPEX, OPEX, raw materials, products, and the EP are calculated for different capacities and shown in Figure 4.
Based on this graph, a plant capacity of $20 \mathrm{t} / \mathrm{hr}$ is able to yield product sales of $\$ 174 \mathrm{mil} / \mathrm{yr}$ with annual OPEX of $\$ 50$ $\mathrm{mil} / \mathrm{yr}$, annual CAPEX of $\$ 5 \mathrm{mil} / \mathrm{yr}$ and annual raw material cost of $\$ 85 \mathrm{mil} / \mathrm{yr}$. This results an EP of $\$ 44 \mathrm{mil} / \mathrm{yr}$. 


\subsection{EO-3 Phosphate Ester (EO-3 PE)}

\subsubsection{Process Flow Diagram}

The developed process flow diagram of the EO-3 PE process is shown in Figure 5. The simulation was also conducted by using ASPEN HYSYS Version 8.8. The components specified are Tergitol 26L-3, phosphoric acid, phosphorous pentoxide, mono-phosphate ester (mono-PE), di-phosphate ester (di-PE), and water. The same thermodynamic model, UNIQUAC Ideal, is chosen as the fluid package.

\subsubsection{Process Description}

The process starts with the esterification reaction between phosphoric acid and Tergitol 26L-3 in a conversion reactor (R101). The reaction operating condition is at $90^{\circ} \mathrm{C}$ and $1 \mathrm{~atm}$. Reaction 1 and 2 occur in this reactor. The product consists of a mixture of liquid (73wt\%) and an aqueous solution (26.9wt\%). The liquid components consist of mono-PE, di-PE, and unreacted tergitol 26L3. The aqueous solution consists of unreacted phosphoric acid.

The aqueous phosphoric acid is separated from the main products before the stream enters the second reactor, R-102. To do that, a simple three-phase separator is used. The esters and unreacted tergitol 26L3 are recovered at the middle stream while the aqueous phosphoric solution is recovered at the bottom as heavy liquids. Unfortunately, the amount of the aqueous phosphoric acid is high with a purity of 75 wt\% of phosphoric acid. Recycling back this high amount of water ( 25 wt\%) into R-101 is not desirable since there may be unknown effect of the water to reactions 1 and 2 .
Therefore, the stream is either purified to be recycled back into R-101 or to be sold as a lower grade phosphoric acid. However, separation of pure phosphoric acid from an aqueous solution is relatively difficult. On the other hand, it was found that there is a market for this low grade phosphoric acid. Hence, in this study, this stream is sold.

The esters and unreacted tergitol $26 \mathrm{~L}-3$ are then sent to R-102 along with phosphorous pentoxide solids. R-102 operates at a vacuum of $2.67 \mathrm{kPa}$ and $90^{\circ} \mathrm{C}$. The solid reacts with the remaining tergitol 26L-3 to produce di-PE according to Reaction 3. Subsequently, the products are then fed into R-103 along with water. R-103 operates at $1 \mathrm{~atm}$ and $90^{\circ} \mathrm{C}$. Here in this reactor, Reaction 4 and 5 occur. 50\% of the di-PE will be converted into mono-PE. A side reaction occurs between the phosphorus pentoxide and water producing aqueous phosphoric acid, and is removed as the vapor phase from the reactor. This aqueous solution will also be sold off as a low grade phosphoric acid.

The liquid products from R-103 is fed to a distillation column ( $T-101)$ to recover any unreacted tergitol 26L-3 and to further purify the esters. T-101 operates at a vacuum pressure of $90 \mathrm{kPa}$ to separate EO-3 PE in the bottom stream. The obtained ester purity is $100 \%$. The mono-ester is about $85 \mathrm{wt} \%$ with the remaining $15 \mathrm{wt} \%$ is the di-ester. The top product consists the unreacted tergitol $26 \mathrm{~L}-3$ and phosphorus pentoxide, which is then recycled back to R-102. Figure 5 shows the developed process flow diagram of the production process of EO-3 PE. A summary of the process material and energy balance in shown in Table 12. 

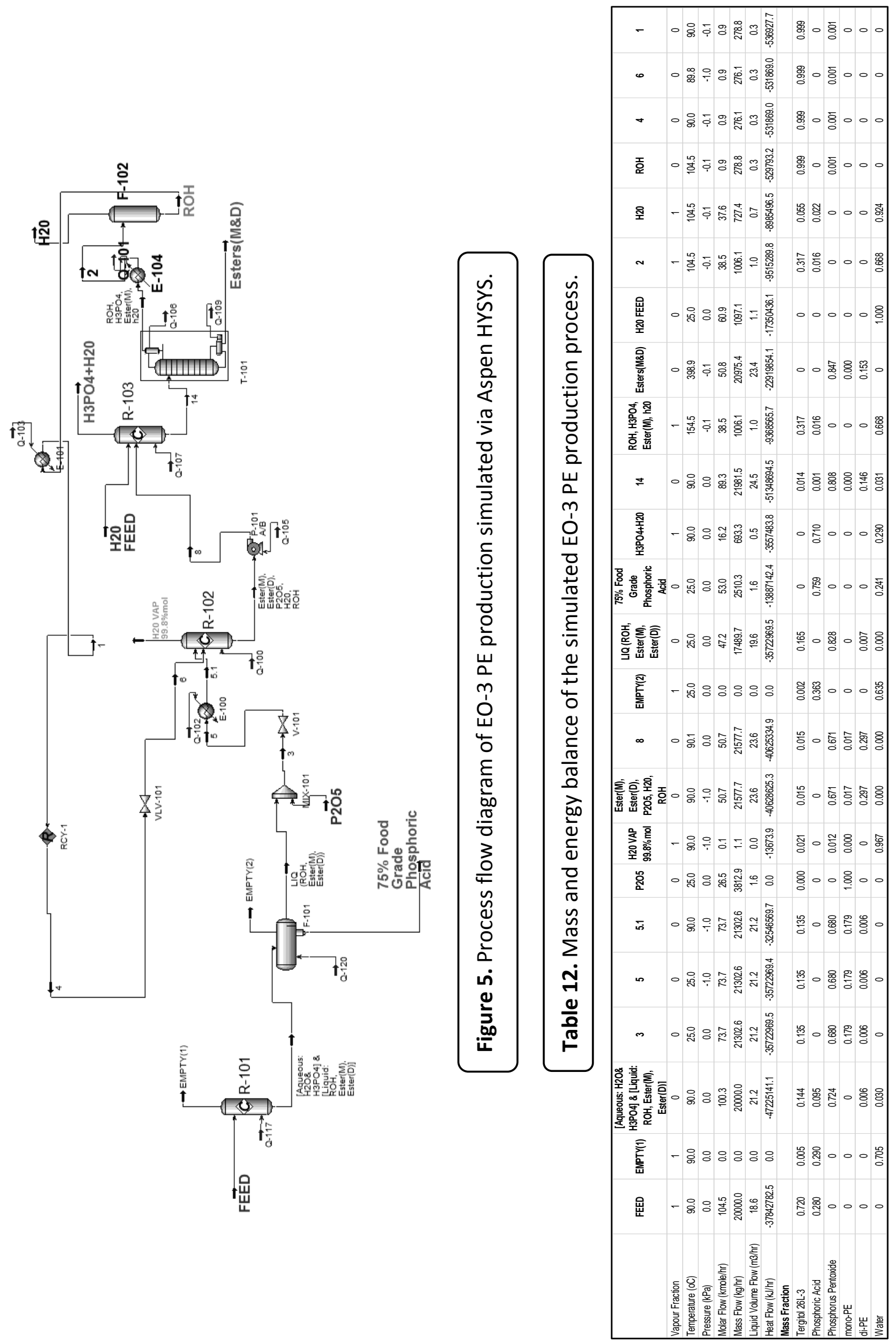


\subsubsection{Economic Analysis}

The same economic calculation is done for the EO-3 PE process and the results are tabulated in Table 14 . These results are plotted in Figure 6.

The graph shows that the lowest per unit CAPEX is about $\$ 3.5$ million/(ton/hr). As the capacity increases further, the estimated CAPEX also increases. It is similar to the economic analysis for the BCA process where the increase is due to the limitation of the sizes of the process equipment.
The same cost sources are taken to be at the same level of accuracy. For this EO-3 PE process, the prices are shown in Table 14. Figure 7 shows the annualized CAPEX, annual OPEX, annual raw material cost and annual product sales, at various flowrates.

Just like in the case of the BCA process, the same observation can be made. For example, a plant capacity of $15 \mathrm{t} / \mathrm{hr}$ creates a product sale of $\$ 1 \mathrm{bil} / \mathrm{yr}$ that requires annual OPEX of $\$ 225 \mathrm{mil} / \mathrm{yr}$, annualized CAPEX of $\$ 6$ $\mathrm{mil} / \mathrm{yr}$ and annual raw material cost of $\$ 169$ $\mathrm{mil} / \mathrm{yr}$. The resulting EP is about $\$ 673 \mathrm{mil} / \mathrm{yr}$.

Table 13. CAPEX per unit capacity of EO-3 PE.

\begin{tabular}{ccc}
\hline Feed capacity (kg/hr) & Product (t/hr) & Capital Expenditure Per Unit (mil \$/) \\
\hline 1 & 1.0 & 10.5 \\
\hline 2 & 2.1 & 7.0 \\
\hline 4 & 4.2 & 5.0 \\
\hline 6 & 6.3 & 4.2 \\
\hline 8 & 8.4 & 3.9 \\
\hline 10 & 10.5 & 3.6 \\
\hline 15 & 15.7 & 3.5 \\
\hline 20 & 20.9 & 3.6 \\
\hline 30 & 31.5 & 3.7 \\
\hline 50 & 52.5 & 4.3 \\
\hline 60 & 62.9 & 5.0 \\
\hline
\end{tabular}

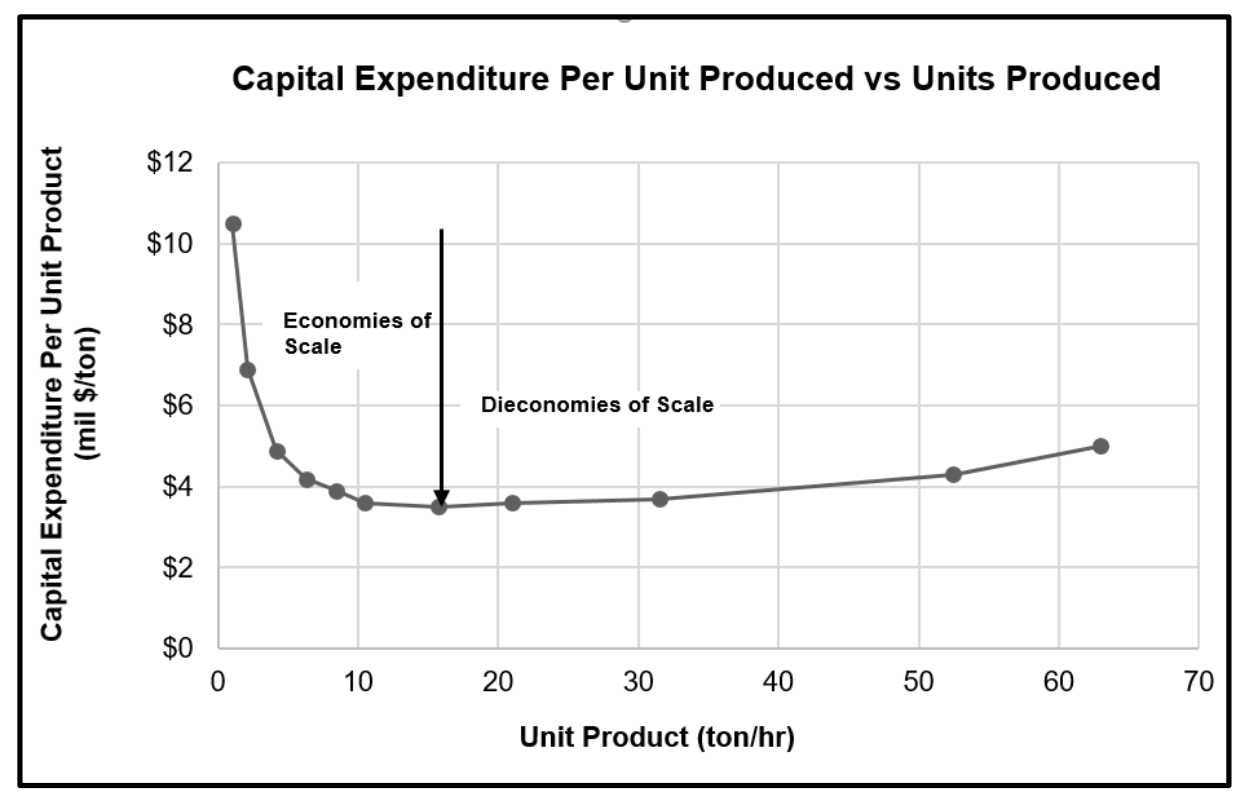

Figure 6. Economies of scale of EO-3 PE process. 
Table 14. . Raw material and product prices for the EO-3 PE.

\begin{tabular}{|c|c|c|c|}
\hline \multirow{2}{*}{\multicolumn{2}{|c|}{ Cost $(\$ / \mathbf{k g})$}} & Raw Material Cost & Product Sale \\
\hline & & \multicolumn{2}{|c|}{ Amount per hour $(\mathrm{kg} / \mathrm{hr})$} \\
\hline Tergitol 26L-3 & 1.22 & 720 & - \\
\hline Phosphoric acid & 0.97 & 280 & - \\
\hline Phosphorous pentoxide & 1.35 & 190.65 & - \\
\hline EO-3 PE & 8.34 & - & 1048.77 \\
\hline Phosphoric acid (food grade) & 0.62 & - & 160.19 \\
\hline \multicolumn{2}{|c|}{ Total Cost $(\$ / \mathrm{hr})$} & $1,407.38$ & $8,846.05$ \\
\hline \multicolumn{2}{|c|}{ Total Cost (mil \$/yr) } & 11.3 & 70.8 \\
\hline
\end{tabular}

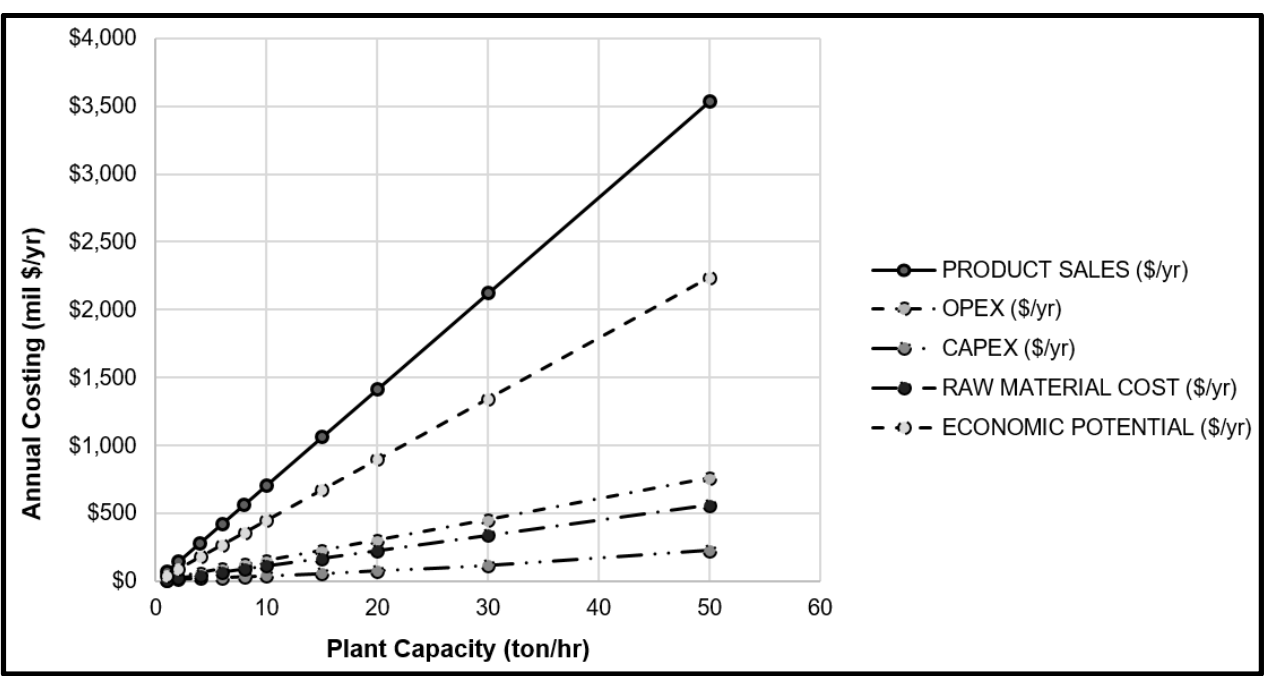

Figure 7. Annualized CAPEX, OPEX, raw material costs, product sales, and the EP of EO-3 PE.

\subsection{Economic Assessment}

Based on Figure 4 and Figure 7, it is observed that at the same feed flow rates, the EO-3 PE production process is more expensive than BCA production process. This is because the required sizes of the reactors in the EO-3 PE process are much bigger, more than the practical limit of vessel sizes as given in the CAPCOST calculations. The bigger sizes are because of the required relatively longer residence times, as indicated from the patent. The residence times in the EO-3 PE process is 3,8 , and 12 hours for reactor 1,2 , and 3 , respectively. On the other hand, the residence times of the BCA process is only 0.05 and 2 hours for reactor 1 and 2, respectively. The more acidic environment also plays a role where this EO-3 PE process require higher grade materials. Hence, the estimated CAPEX for the EO-3 PE is higher than that for the BCA process.

Nevertheless, this high CAPEX value is offset by the higher product price of EO-3 PE. EO-3 PE is sold at $\$ 8.34$ per $\mathrm{kg}$, while BCA is sold at $\$ 1.19$ per $\mathrm{kg}$. This causes the economic potential of the EO-3 PE to be much higher than that of the BCA. In addition to that, the production process of EO-3 PE is simpler compared to BCA process, where the only by-product is phosphoric acid, which can be sold off as a $75 \mathrm{wt} \%$ food grade phosphoric acid. This also adds to the more favorable EO-3 PE process. 
The BCA process itself requires more separation processes because of its lower selectivity and difficulties in separating the desired product from the lights and heavy byproducts, as well as to recover the catalyst. This downstream process increases the utility costs. Thus, it can be concluded here that since EO-3 PE is simpler to produce and has a higher economic potential, the EO-3 PE is the more profitable ester to produce.

\subsection{Monte-Carlo Simulation}

To evaluate the effect of the uncertainties in the capital cost estimates as well as the prices of the chemicals, Monte Carlo simulation is performed as explained above. The same capacity of $20 \mathrm{ton} / \mathrm{hr}$ is used as the base-case for both the BCA and the EO-3 PE processes. The results for the BCA process is shown in Figure $\mathbf{8}$. The $x$-axis shows the calculated Economic Potential (EP) of each event compared to the base-case. The $y$-axis shows the frequency of how many times the corresponding event happens. The result shows that this BCA production process can apparently create higher chance of economic losses. It is seen from the estimated negative values of EP compared to its base-case.

This simulation result of the BCA process is then compared with that of the EO-3 PE process. This comparison is shown in Figure 9. Even though that the EO-3 PE process has wider variations of $E P$, the compared results show that the two processes are clearly distinct. The EO-3 PE process is significantly more profitable than the BCA process. Hence, it can be concluded that the EO-3 PE process is more profitable to build compared to the BCA process.

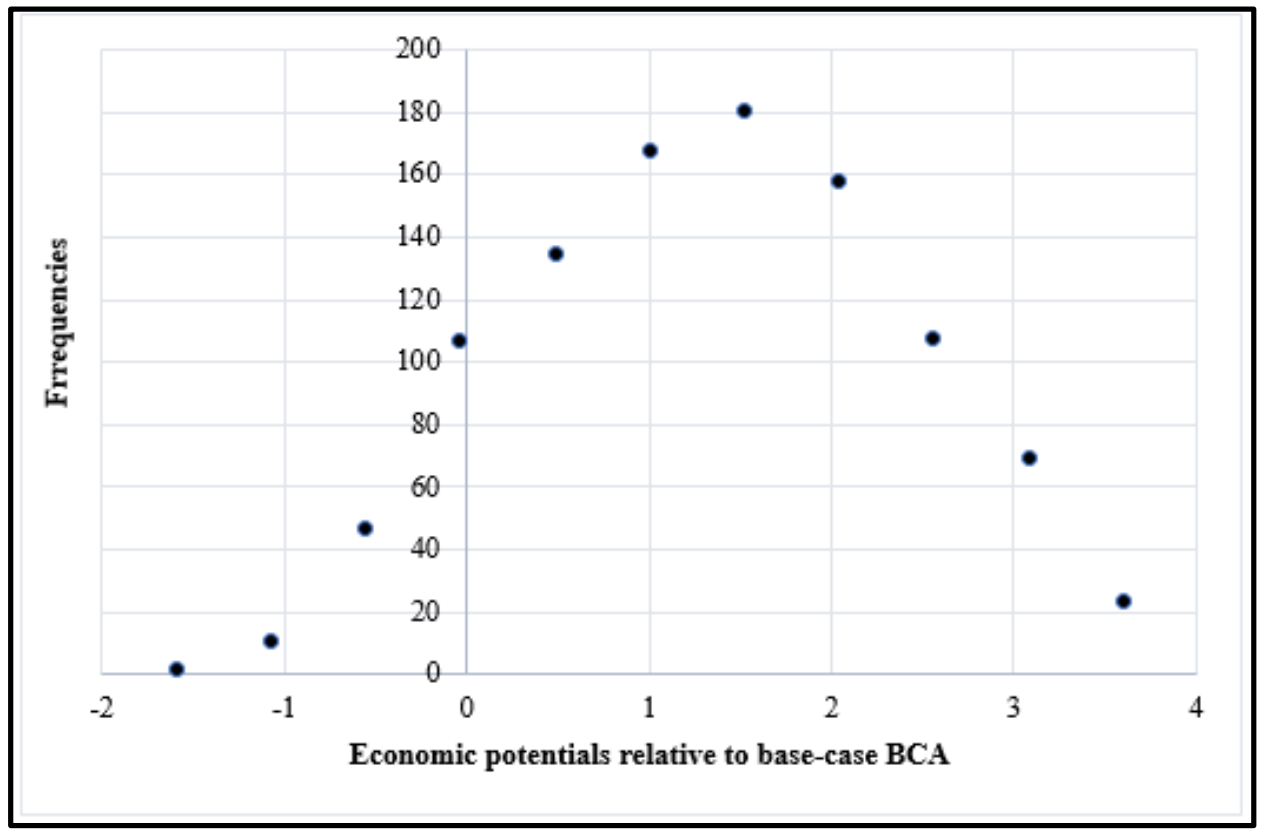

Figure 8. Monte Carlo simulation of the EP of BCA process compared to the base-case 


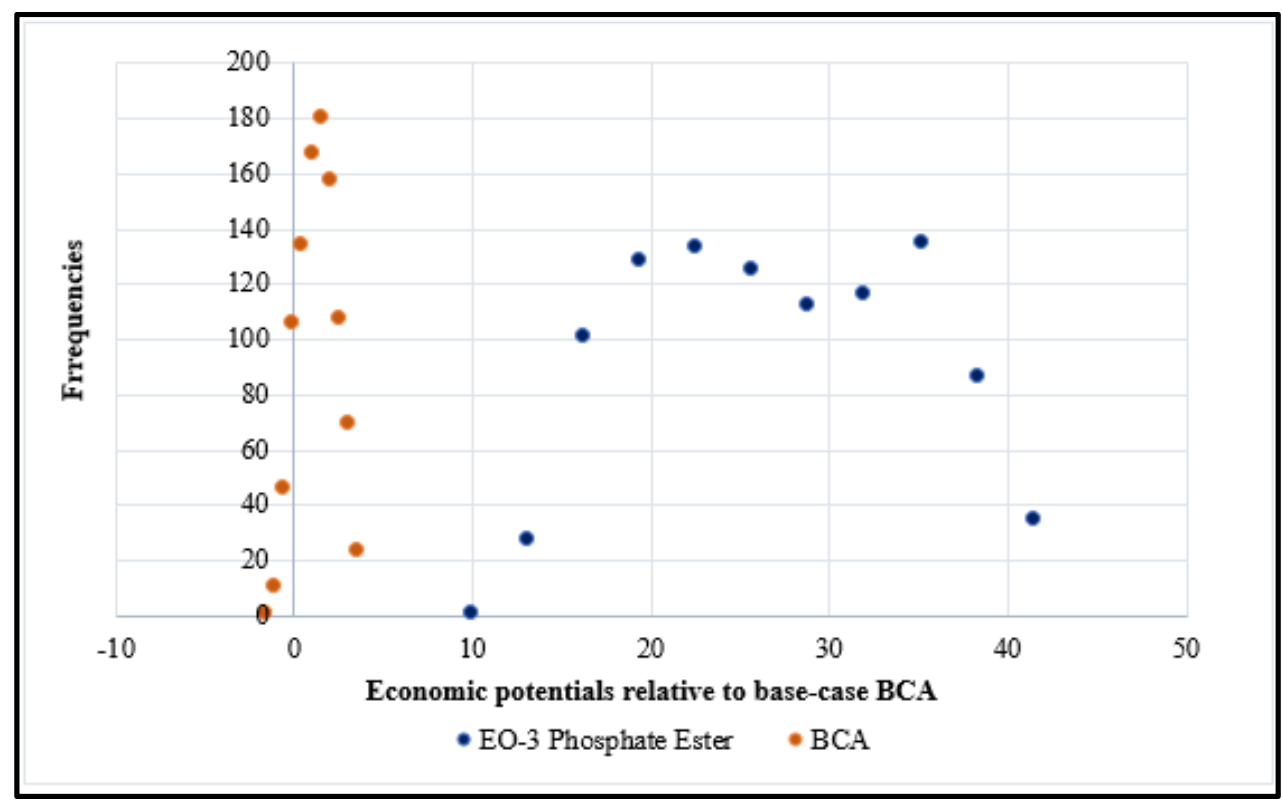

Figure 9. Monte Carlo simulations for both BCA and EO-3 PE processes.

\section{CONCLUSION}

Two ester production processes have been developed, namely the BCA and the EO3 PE processes. Their technical challenges have been observed and the economic feasibility was compared to determine the most profitable process. Technically, the environment of the EO-3 PE production process is more acidic and it requires relatively longer residence times. Hence, its estimated CAPEX is much higher compared to that of the BCA process. On the other hand, lower selectivity and difficult separations between the by-products, unreacted raw materials, and the BCA product itself lead to higher utility costs of the BCA process.

Nonetheless, the economic potential of EO-3 PE is higher than that of BCA because the EO-3 PE product is found to be much more expensive. Sensitivity analysis via Monte-Carlo simulation shows that the EO-3
PE process is always and significantly more profitable compared to the BCA process.

Future works to further develop the EO3 PE process include gathering more information on the series of reactions involved in the production of EO-3 PE. This includes, among others, the required operating condition window, effect of impurities to the reactions, and the accuracy of the estimated thermodynamic properties.

\section{ACKNOWLEDGEMENT}

The author gratefully acknowledges the financial support and facilities provided by Universiti Teknologi PETRONAS (UTP) upon completion of this final year project.

\section{AUTHORS' NOTE}

The author(s) declare(s) that there is no conflict of interest regarding the publication of this article. Authors confirmed that the data and the paper are free of plagiarism. 


\section{REFERENCES}

Borole, A. P., \& Davison, B. H. (2007). Techno-economic analysis of biocatalytic processes for production of alkene epoxides. Applied Biochemistry and Biotecnology, 437-449.

Dal Pont, J. P., \& Azzaro-Pantel, C. (2014). New Appoaches in the Process Industries: The Manufacturing Plant of the Future. John Wiley \& Sons.

D'Alessandro, D. M., Smit, B., \& Long, J. R. (2010). Carbon dioxide capture: prospects for new materials. Angewandte Chemie International Edition, 49(35), 6058-6082.

Deng, L., \& Hägg, M. B. (2010). Techno-economic evaluation of biogas upgrading process using CO 2 facilitated transport membrane. International Journal of Greenhouse Gas Control, 4(4), 638-646.

Keen B.T., Papa A.J., U.C.C. \& P.T. CORPORATION, Esterification process, 1995.

Landucci, R., Goodman, B., \& Wyman, C. (1994). Methodology for evaluating the economics of biologically producing chemicals and materials from alternative feedstocks. Applied biochemistry and biotechnology, 45(1), 677-696.

$\mathrm{Li}, \mathrm{H}$. Y. (1990). Mechanisms of action and selectivity of the cyclohexen-one herbicide cycloxydim (BAS 517) (Doctoral dissertation, Virginia Tech).

Mitsunobu, O., \& Yamada, M. (1967). Preparation of esters of carboxylic and phosphoric acid via quaternary phosphonium salts. Bulletin of the Chemical Society of Japan, 40(10), 2380-2382.

Peters, M. S., Timmerhaus, K. D., West, R. E., Timmerhaus, K., \& West, R. (1968). Plant design and economics for chemical engineers (Vol. 4). New York: McGraw-Hill.

Pintarič, Z. N., \& Kravanja, Z. (2015). The importance of proper economic criteria and process modeling for single-and multi-objective optimizations. Computers \& Chemical Engineering, 83, 35-47.

Putra, Z. A. (2016a). Early phase process evaluation: Industrial practices. Indonesian journal of science and technology, 1(2), 238-248.

Putra, Z. A. (2016b). Use of Process Simulation for Plant Debottlenecking. Indonesian Journal of science and technology, 1(1), 74-81.

Russell, C. A. (Ed.). (2000). Chemistry, society and environment: a new history of the British chemical industry. Royal Society of Chemistry.

Stine, C. M. (1933). Relation of Chemical to Other Industry. Industrial \& Engineering Chemistry, 25(5), 487-495.

Tsuyutani, S., Shibata, K., Aizawa, K., Sakata, M., \& Morishita, M. (2004). U.S. Patent No. $6,710,199$. Washington, DC: U.S. Patent and Trademark Office. 